\title{
Regionalization of the shark hindbrain: a survey of an ancestral organization
}

\section{Isabel Rodríguez-Moldes ${ }^{1}$, , Ivan Carrera ${ }^{1}$, Sol Pose-Méndez', Idoia Quintana-Urzainquii', Eva Candal', Ramón Anadón', Sylvie Mazan ${ }^{2}$ and Susana Ferreiro-Galve ${ }^{1}$}

\author{
1 Department of Cell Biology and Ecology, University of Santiago de Compostela, Santiago de Compostela, Spain \\ 2 UMR 7150, Centre National de la Recherche Scientifique, Université Pierre et Marie Curie and Université Européene de Bretagne, Station Biologique de Roscoff, \\ Roscoff, France
}

\section{Edited by:}

Luis Puelles, University of Murcia,

Spain

\section{Reviewed by:}

Faustino Marin, University of Murcia, Spain

Luis Puelles, University of Murcia, Spain

\section{*Correspondence:}

Isabel Rodríguez-Moldes, Department of Cell Biology and Ecology, University of Santiago de Compostela, Building CIBUS, South Campus, 15782 Santiago de Compostela, Spain e-mail: isabel.rodriguez-moldes@usc.es
Cartilaginous fishes (chondrichthyans) represent an ancient radiation of vertebrates currently considered the sister group of the group of gnathostomes with a bony skeleton that gave rise to land vertebrates. This out-group position makes chondrichthyans essential in assessing the ancestral organization of the brain of jawed vertebrates. To gain knowledge about hindbrain evolution we have studied its development in a shark, the lesser spotted dogfish Scyliorhinus canicula by analyzing the expression of some developmental genes and the origin and distribution of specific neuronal populations, which may help to identify hindbrain subdivisions and boundaries and the topology of specific cell groups. We have characterized three developmental periods that will serve as a framework to compare the development of different neuronal systems and may represent a suitable tool for comparing the absolute chronology of development among vertebrates. The expression patterns of Pax6, Wnt8, and HoxA2 genes in early embryos of $S$. canicula showed close correspondence to what has been described in other vertebrates and helped to identify the anterior rhombomeres. Also in these early embryos, the combination of Pax 6 with protein markers of migrating neuroblasts (DCX) and early differentiating neurons (general: HuC/D; neuron type specific: GAD, the GABA synthesizing enzyme) revealed the organization of $S$. canicula hindbrain in both transverse segmental units corresponding to visible rhombomeres and longitudinal columns. Later in development, when the interrhombomeric boundaries fade away, accurate information about $S$. canicula hindbrain subdivisions was achieved by comparing the expression patterns of Pax6 and GAD, serotonin (serotoninergic neurons), tyrosine hydroxylase (catecholaminergic neurons), choline acetyltransferase (cholinergic neurons), and calretinin (a calcium-binding protein). The patterns observed revealed many topological correspondences with other vertebrates and led to reconsideration of the current view of the elasmobranch hindbrain segmentation as peculiar among vertebrates.

Keywords: rhombomeres, HoxA2, Wnt8, calretinin, cartilaginous fishes, shark embryo, development, evolution

\section{INTRODUCTION}

In elasmobranchs, as in other vertebrates, two prominent external constrictions divide the early developing brain (neural tube) into the three neural vesicles giving rise to the basic regions of the adult brain: forebrain (or prosencephalon), midbrain (or mesencephalon), and hindbrain (or rhombencephalon). These vesicles represent the fundamental antero-posterior (i.e., rostrocaudal)

Abbreviations: AOL, octavolateral area; br1-br4, branchial arches; c1-c2, pharyngeal clefts 1-2; cer, cerebellum; $\mathrm{H}$, hypophysis; IIIm, oculomotor nucleus; IIIn, oculomotor nerve; IVm, trochlear motor nucleus; IXm, glossopharyngeal motor nucleus; IXn, glossopharyngeal nerve; LC, locus coeruleus; Mes, mesencephalon; mlf, medial longitudinal fascicle; n, notochord; Oli, inferior olive; os, optic stalk; ot, otic placode; p1-p3, prosomeres; ph1-ph3, pharyngeal pouches; Pal, pallium; Pros, prosencephalon; R, Rathke's pouch; r1-r8, rhombomeres; Ra, raphe (medial) cells of the reticular formation; Re, reticular (lateral) cells of the reticular formation; Rh, rhombencephalon; Sc, nucleus subcoeruleus; Sp, subpallium; spc, spinal cord; SV, saccus vasculosus; VIIIm, magnocellular octaval nucleus; VIIIn, octaval nerve; VIIm, facial motor nucleus; VIIn, facial nerve; VIM, visceromotor area; VIm, abducens nucleus; VIn, abducens nerve; VIS, viscerosensory lobe; Vm, trigeminal motor nucleus; Vn, trigeminal nerve; Xm, vagal motor nucleus; Xn, vagal nerve. subdivisions that later on may become subdivided into more or less evident transverse bands or neuromeres, which have defined relations with other structures of the head and the peripheral nervous system, being very useful in comparative studies. In the hindbrain, these transverse units, called rhombomeres, exhibit a segmental organization and appear as prominent ventricular outpouchings separated by constrictions. Coinciding with the emergence of rhombomeres, longitudinal zones with distinct morphological and functional identity become organized along the brain and spinal cord. Four columns separated by ventricular sulci have been commonly recognized in the adult shark hindbrain: ventral and ventrolateral columns (derived from the basal plate), and dorsolateral and dorsal columns (derived from the alar plate). These columns represent the classical four functional zones (Gaskell, 1886, 1889; Herrick, 1918): the alar plate-derived somato- and viscerosensory columns and the basal plate-derived viscero- and somatomotor columns. Taking into account this developmental pattern, the different hindbrain regions and nuclei have been usually assigned to longitudinal bands and segmental units. However, this classic 
conception is under revision after the identification of molecular markers that revealed distinct longitudinal subdivisions in these columns (Briscoe et al., 2000; Sieber et al., 2007) and because of the existence of migratory processes in basal plate-born motoneurons that reached the alar plate (Ju et al., 2004).

Understanding brain segmentation has become essential for comparative neuroanatomical studies. In particular, studies in different vertebrate groups have revealed that the segmental organization of rhombencephalic structures is rather well conserved in evolution (Gilland and Baker, 1993, 2005; Marín and Puelles, 1995; Pritz, 1999; Cambronero and Puelles, 2000; Straka et al., 2002). Comparative studies have also pointed some variations among vertebrates in the organization of individual hindbrain segments (Gilland and Baker, 1993, 2005), but their evolutionary significance has not been cleared yet. Some neurochemical markers were found helpful in studies about hindbrain organization, since they can identify neuronal populations that show segmental patterns. Among them, calretinin (CR, a calcium-binding protein) has proven to be a useful tool to identify hindbrain subpopulations (Marín and Puelles, 1995; Pritz, 1999; Díaz-Regueira and Anadón, 2000; Castro et al., 2006; Morona and González, 2009). Other markers such as choline acetyltransferase (ChAT), serotonin (5-HT), or tyrosine hydroxylase (TH) have also been used to examine the segmental organization of the hindbrain in different vertebrate species, including elasmobranchs (Anadón et al., 2000; Carrera et al., 2005, 2008).

Our present aim is to contribute to knowledge about hindbrain regionalization in a small shark, the lesser spotted dogfish Scyliorhinus canicula, by highlighting some aspects of its development. This common coastal dogfish is becoming the prevailing chondrichthyan model in comparative neurobiology and developmental studies (Coolen et al., 2009). The fairly transparent eggs can be easily maintained in the laboratory until hatching, which occurs 6 months after fertilization. The protracted development and the relatively large size of the embryonic brain allow a detailed analysis of developmental processes. To know how regionalization is achieved, we have analyzed the expression of some developmental genes involved in the transverse segmentation of the anterior hindbrain. In particular, we have used HoxA2 and Wnt8 because the former is the only Hox gene expressed in rhombomere 2 ( $\mathrm{r} 2$; Tümpel et al., 2008; Alexander et al., 2009) and the latter seems to be responsible for the determination of rhombomere 4 (r4) identity (Bouillet et al., 1996). Furthermore, we have analyzed the development of specific neuronal populations using markers that proved to be very useful to identify topographically restricted neuronal populations relative to brain subdivisions and/or segmental boundaries. We have constrained the characterization of transverse and longitudinal subdivisions of $S$. canicula hindbrain at early and intermediate embryonic stages. The results of this study bear on how the hindbrain of cartilaginous fish becomes organized and about possible ancestral features of hindbrain regionalization. The results described are consistent with the model that advocates the evolutionary conservation of the segmental rhombencephalic entities (Gilland and Baker, 1993, 2005; Marín and Puelles, 1995; Pritz, 1999; Cambronero and Puelles, 2000; Straka et al., 2002) which is useful for comparative purposes. This helps understanding how hindbrain development evolved during phylogeny.

\section{MATERIALS AND METHODS EXPERIMENTAL ANIMALS}

Embryos of the lesser spotted dogfish (S. canicula) were provided by the Oceanário in Lisbon (Portugal), and the Aquarium Finisterrae in A Coruña (Spain). Additional embryos were supplied by the Station Biologique de Roscoff (France). Embryos of S. canicula were staged according to Ballard et al. (1993). The following stages were analyzed: stage 20 (four pairs of unopened pharyngeal pouches visible by translucence), stage 22 (two pairs of pharyngeal clefts open), stage 23 (three pairs of pharyngeal clefts open), stage 24 (diamondshaped mouth), stage 25 (four pairs of open pharyngeal clefts), stages 26 (five pairs of open pharyngeal clefts, simple gill bars), stage 27 (diamond-shaped mouth and primordial gill filaments), stage 28 (transverse oval mouth, gills with external filaments), stage 29 (mandibular arches crowded into the mouth opening and initial eye pigmentation), stages 30 (eyeballs circled with black pigment), stage 31 (detectable rostrum and long branchial filaments), stage 32 (regression of branchial filaments), stages 33 and 34 (prehatching).

\section{TISSUE PREPARATION}

All procedures conformed to the guidelines established by the European Communities Council Directive of 24 November 1986 (86/609/EEC) and by the Spanish Royal Decree 1201/2005 for animal experimentation and were approved by the Ethics Committee of the University of Santiago de Compostela. Embryos were anesthetized with $0.5 \%$ tricaine methane sulfonate (MS-222; Sigma, St. Louis, MO, USA) in seawater and fixed in 4\% paraformaldehyde (PFA) in elasmobranch phosphate buffer containing urea for 48-72 h depending on the stage, as described by Carrera et al. (2008). Parallel series of 14-18 $\mu \mathrm{m}$ thick sections were obtained after cryostat sectioning of specimens in sagittal, transverse, or horizontal planes in relation to the main body axis.

\section{IN SITU HYBRIDIZATION}

We applied in situ hybridization for ScPax6 (Derobert et al., 2002), ScWnt8 (Coolen et al., 2007), and ScHoxA2 (Oulion et al., 2010). These probes were selected from a collection of S. canicula embryonic cDNA library (mixed stages, S9 to 22), submitted to high throughput EST sequencing (coord. S. Mazan).Sense and antisense digoxigeninUTP-labeled RNA probes were synthesized directly by in vitro transcription using as templates linearized recombinant plasmid DNA (Pax6 probe) or cDNA fragments prepared by PCR amplification of the recombinant plasmids (ScWnt8 and ScHoxA2 probes).

Whole-mount in situ hybridization was carried out in S20, S22, and S24 embryos following standard protocols (Coolen et al., 2007). Briefly, embryos were permeabilized with proteinase $\mathrm{K}$, hybridized with sense or antisense probes overnight at $70^{\circ} \mathrm{C}$ and incubated with the alkaline phosphatase-coupled anti-digoxigenin antibody (1:2000, Roche Applied Science, Mannheim, Germany) overnight at $4^{\circ} \mathrm{C}$. The color reaction was performed in the presence of BM-Purple (Roche). Control sense probes did not lead to any detectable signal.

\section{IMMUNOHISTOCHEMISTRY}

Sections were processed for the ABC method (single labeling) or for double immunofluorescence following Ferreiro-Galve et al. (2010). As primary antibodies we used polyclonal rabbit anti-Pax6 (Covance; dilution 1:400) or polyclonal goat anti-Pax6 (Novus Biologicals; dilution: 1:200), polyclonal rabbit anti-sonic hedgehog 
(Shh; Santa Cruz Biotech.; dilution 1:300) polyclonal rabbit antiCR (Swant; dilution 1:250-500), polyclonal rabbit anti-serotonin (5-HT; Diasorin/Immunostar; dilution 1:5,000); polyclonal rabbit anti-doublecortin (DCX; Cell Signaling; dilution 1:300-500) or polyclonal goat anti-DCX (Santa Cruz Biotech.; dilution 1:100); monoclonal mouse anti-TH (Millipore; dilution 1:500-1,000), monoclonal mouse anti-proliferating cell nuclear antigen (PCNA; Sigma; dilution 1:200), monoclonal mouse anti-HuC/D (Molecular Probes; dilution 1:200), and polyclonal sheep anti-GAD65/67 (GAD 1440; kindly provided by Dr. E. Mugnaini; dilution 1:20,000).

For single immunoperoxidase labeling, sections were pretreated to remove the endogenous biotin-like and peroxidase activities, as described by Sueiro et al. (2004). As secondary antibody we used a biotinylated goat anti-rabbit or anti-mouse antiserum, appropriately to the primary antibody employed (Dako; dilution 1:500), followed by incubation with the preformed avidin-biotinylated horseradish peroxidase complex (Vector Laboratories). The immunoreaction was finally developed, either with $0.25 \mathrm{mg} / \mathrm{ml}$ diaminobenzidine tetrahydrochloride (DAB; Sigma) containing $2.5 \mathrm{mg} / \mathrm{ml}$ nickel ammonium sulfate and $0.00075 \% \mathrm{H}_{2} \mathrm{O}_{2}$ (blue precipitate), or with SIGMAFAST ${ }^{\mathrm{TM}} 3,3^{\prime}$-DAB tablets (brown precipitate).

For double immunofluorescence, the following secondary antibodies were used: Alexa Fluor 488-conjugated donkey antirabbit immunoglobulin (Molecular Probes; diluted 1:200) and FluoProbes 546-conjugated donkey anti-mouse (Interchim; diluted 1:100), TRITC-conjugated swine anti-rabbit immunoglobulin (Dako; diluted 1:100), Alexa Fluor 488-conjugated donkey antisheep immunoglobulin (Molecular Probes; diluted 1:100). Sections were photographed with a fluorescence microscope fitted with an Olympus DP 70 color digital camera and a Leica Spectral Confocal Laser Scanning Microscope (TCS-SP2).

Embryos processed in toto for in situ hybridization with ScWnt8 were sectioned on cryostat in sagittal plane at $18-20 \mu \mathrm{m}$ thick and then sections were treated for immunohistochemistry for rabbit anti-DCX as described previously for immunoperoxidase labeling.

\section{RESULTS AND DISCUSSION PERIODS OF BRAIN DEVELOPMENT IN THE LESSER SPOTTED DOGFISH}

In order to establish an outline for comparative studies, we distinguished three periods in the development of the lesser spotted dogfish, based on the histogenetic stage of the brain walls (Table 1). During the first period (from embryo stages 17-26), the neural walls mainly consist of a thick proliferating neuroepithelium. Late during this period, radially migrating neuroblasts are first noticed and a primordial mantle layer appears. During the second period (from embryo stages 27-31) the brain walls are subdivided radially into the standard three primary layers or zones (ventricular, mantle/ intermediate, marginal/subpial). During this period, cell proliferation, migration, and differentiation are very active and lead to the topological organization of most neuronal systems and the differentiation of the major pathways. The majority of brain catecholaminergic and serotoninergic cell populations develop during this time (Carrera et al., 2005, 2008). During this second period the morphological differentiation of the main brain centers occurs. The third period is the longest one (3 months, just a half of the embryonic period) and corresponds to the prehatching period of Ballard et al. (1993). It starts at stage 32, when the embryo looks like a small juvenile with an attached yolk sac. In the brain, cell proliferation is still very active in some ventricular regions, and migrating neuroblasts are also present in some regions; but most neurons have already migrated away from the ventricular zone. Distinct cells groups are hardly recognized with conventional staining, because of the considerable dispersion of mantle cells, but boundaries can be discerned by their neurochemical content. During this stage, most neuronal populations observed in juveniles and adults are established, although morphogenesis continues in some brain regions. The third period thus can be considered as a period of brain maturation.

Since a similar histogenetic sequence occurs in the brain of all vertebrates, the corresponding relative timing of periods can be used as a framework for comparative studies. The three developmental periods described in S. canicula can be roughly recognized in other vertebrates, although the time of occurrence varies largely as a result of sizeable differences in the length of the embryonic period (Table 1).

\section{REGIONALIZATION OF THE HINDBRAIN IN EARLY EMBRYOS (FIRST DEVELOPMENTAL PERIOD) \\ Transverse segmental regions}

During S. canicula development, as in other vertebrates, prominent ventricular ridges divide the rhombencephalon into transverse segmental units exhibiting shallow ventricular outpouchings and corresponding outer bulges, the rhombomeres. Six apparently interrhombomeric limits can be clearly identified in the hindbrain of early S. canicula embryos.

Table 1 | Correspondence among embryonic developmental stages of different vertebrate embryos according to the three development periods defined in S. canicula and some external features.

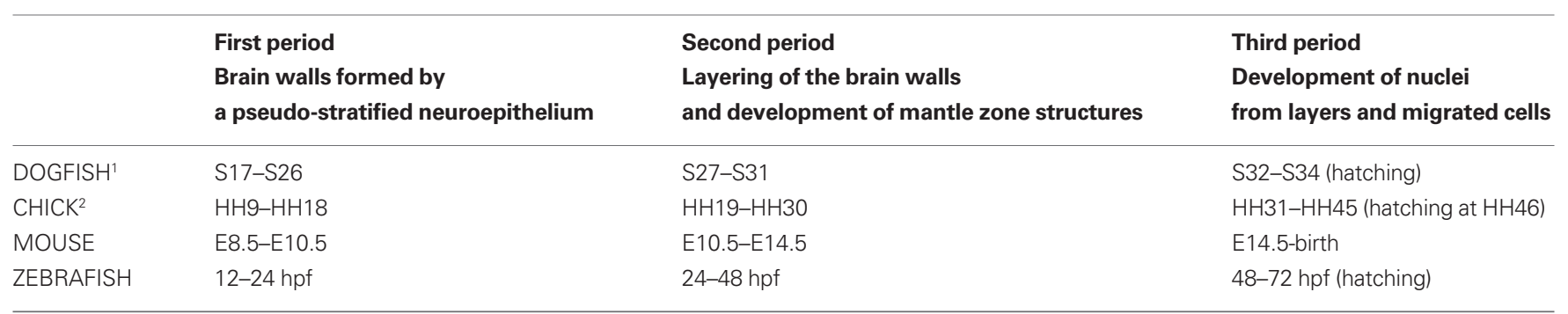

'Stages from Ballard et al. (1993).

${ }^{2}$ Stages from Hamburger and Hamilton (1951). 
The analysis of the expression of the ScHoxA2 gene has revealed an interesting finding. In the early $S$. canicula embryos analyzed this gene was expressed along several rhombomeres with a sharp anterior limit of expression at the level of a conspicuous interrhombomeric boundary (Figures 1A-C). Assuming that in dogfish, as in other vertebrates (Prince et al., 1998; Glover, 2001; Tümpel et al., 2008), the anterior limit of HoxA2 expression coincides with the r1/r2 boundary, we could identify the rhombomeres 1 and 2 (r1 and r2)
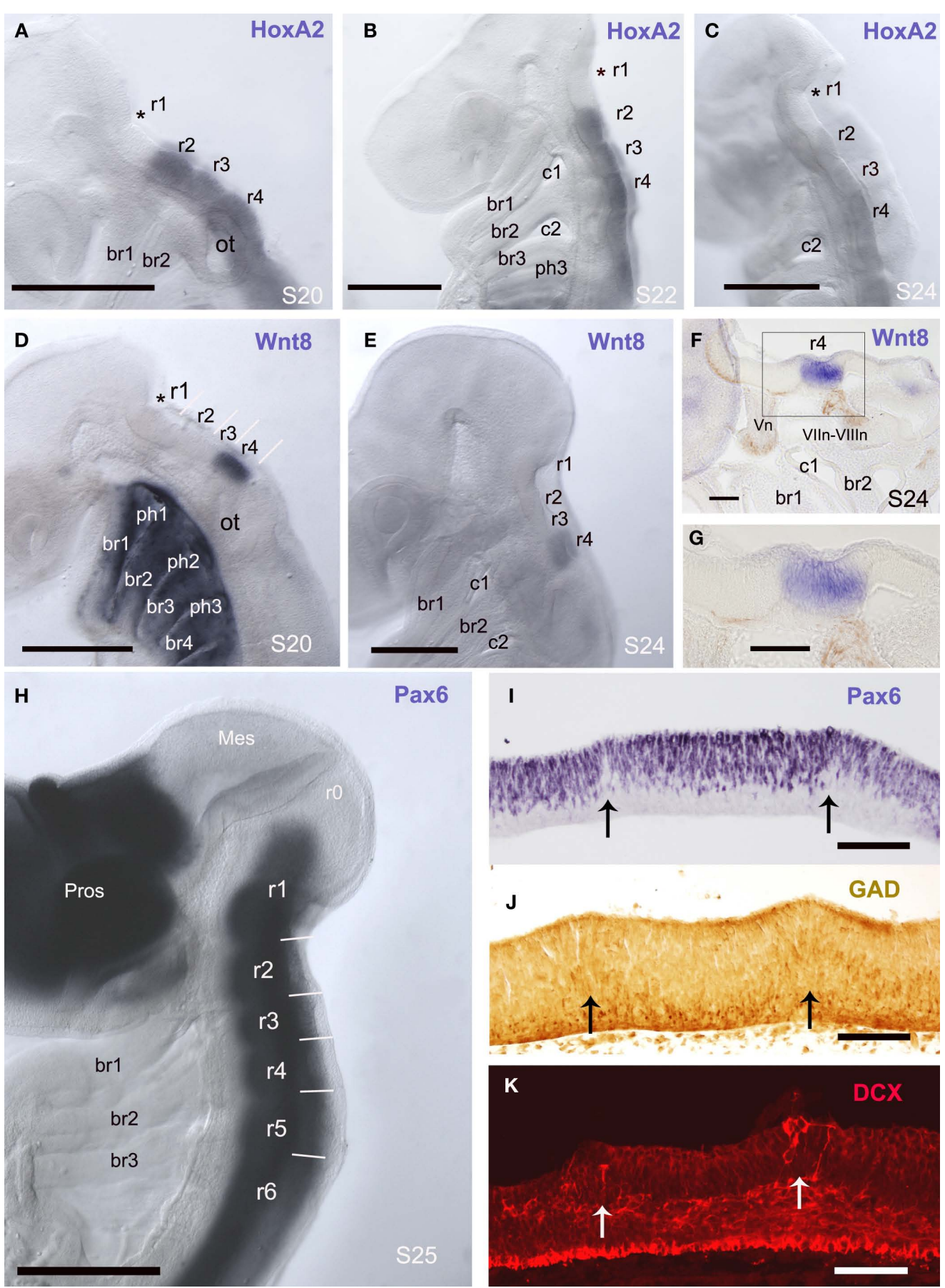

\section{FIGURE 1 | Rhombomeres are visible in early embryos as the} interrhombomeric limits are evident. (A-H) Whole-mount in situ hybridization for ScHoxA2 (A-C), ScWnt8 (D-G), and ScPax6 (H) in the early developing embryo in lateral view at the indicated developmental stages. Asterisks in (A-D) label the rostralmost intrarhombomeric ventricular ridge at $\mathrm{r}$ 1. $(\mathbf{F}, \mathbf{G})$ are panoramic and detail of a sagittal section of a S24 embryo whole-mount processed for in situ hybridization showing ScWnt8 expression in r4 (in blue) where DCX-immunoreactive fibers of the acoustic-facial nerve roots emerge. (I-K) Parasagittal sections immunolabeled for Pax6 (I), GAD (J), and DCX (K) showing ventricular ridges that coincide with interrhombomeric limits. At these boundaries low density of Pax6 cells (I), radially oriented GAD-ir (J) and DCX (K) cells are observed. Scale bars: $500 \mu \mathrm{m}(\mathbf{A}-\mathbf{E}, \mathbf{H}) ; 100 \mu \mathrm{m}(\mathbf{F}, \mathbf{G}, \mathbf{I}, \mathbf{J})$ 
of S. canicula as showed in Figures 1A-C. As the anterior limit of expression of ScHoxA 2 coincides with the $\mathrm{r} 1 / \mathrm{r} 2$ boundary, and the position of the rostralmost ScHoxA2-expression rhombomere is adjacent to the position of the trigeminal ganglion (see Figure 3 of O'Neill et al., 2007), we have identified the rhombomere 2 of S. canicula as the rostralmost rhombomere expressing HoxA2 (Figures 1A-C). Interestingly, we have noted that in S. canicula the $\mathrm{r} 1 / \mathrm{r} 2$ boundary is not the rostralmost ventricular ridge since an intrarhombomeric ventricular ridge is recognized anteriorly (asterisks in Figures 1A-C). Considering the actual extension of r1 inferred by the lack of HoxA2 expression, we questioned the identification of rhombomeres in S. canicula embryos on the basis of the expression of the Ephrin receptor EphA4 described by Freitas and Cohn (2004), in particular the rhombomere 3 (compare their Figure 2d with our Figure 1B, both from stage 22).

The expression pattern of the $S c W n t 8$ gene in early embryos has allowed to identify unequivocally rhombomeres 3 and 4 . In early pharyngula stages (S20), the expression of this gene was very intense and exclusively of one rhombomere, which was caudal but not adjacent to 2 2. Later in development (S24, late pharyngula) ScWnt8 expression was maintained in the same rhombomere but with a weaker signal. Considering that the rhombomere 4 in mouse shows the latest detectable expression of Wnt8 (Bouillet et al., 1996), we postulate that in S. canicula embryos the ScWnt8-expressing rhombomere also corresponds to $\mathrm{r} 4$. Moreover, in whole-stained embryos the position of rhombomeres 2 and 4 showed a correspondence with the position of branchial arches (Figures 1B,D-F). In addition, sections of ScWnt8-hybridized embryos and immunohistochemically stained with the anti-DCX antibody revealed that the roots of the VII-VIII nerves (which in all vertebrates studied exit from $\mathrm{r} 4$, see below) emerge from the ScWnt8-expressing rhombomere (Figures 1F-G).

Pax6-expressing cells formed a continuous column along the basal rhombencephalon and the spinal cord. As in other gnathostomes, the expression of Pax6 is observed in all S. canicula rhombomeres (Figure $\mathbf{1 H}$ ) even at very early stages, in contrast with agnathans, in which Pax6 expression in rhombomere 4 is delayed in relation to other rhombomeres (Murakami et al., 2001; Derobert et al., 2002).

Transverse segmental bands that match with morphologically noticeable rhombomeres were observed in parasagittal sections of S26 embryos stained to show the distribution of Pax6-positive cells and GABAergic cells (Figures 1I,J). Interrhombomeric limits appeared as a series of small ventricular ridges corresponding laterally with Pax6-poor gaps separating Pax6-rich bulges. The similarity between the hindbrain ventricular profiles of $S$. canicula embryos at stage 26 and those reported in chick embryos at stage HH18 (Heyman et al., 1993) supports our proposal of equivalences in developmental periods in various vertebrates (see Table 1). There was a markedly lower density of Pax6-positive cells at the ventricular ridges (arrows in Figure 1I), which was more notable at later stages. The distribution of GABAergic cells in relation to the interrhombomeric boundaries is also of interest (Figure 1J). Numerous GABAergic cells adopting a fan-shaped alignment formed wedgeshaped crests in the mantle layer, which pointed toward the ventricular surface. Within these crests, apical GABAergic cells showed a short apical process and displayed the appearance of radially migrating cells, while the rest of GABAergic cells at the intermediate layer sent longer processes into the marginal layer. In addition, migrating neuroblasts identified by their immunolabeling for DCX were observed in these areas (Figure 1K).

Although in early embryos the interrhombomeric constrictions only allowed to distinguish clearly rhombomeres $1-6(\mathrm{r} 1-\mathrm{r} 6)$, we have also contemplated the existence of additional rhombomeres flanking them rostrally (r0) and caudally (r7 and r8; Figure 2).

The rhombomere 0 ( $\mathrm{r} 0$; Puelles, 2001; Aroca and Puelles, 2005) is the rostralmost rhombencephalic segment, and corresponds to the isthmic territory. The continuous column of Pax6-immunoreactive cells observed in the rhombencephalon of early S. canicula embryos does not extend to the constriction that marks the midbrain-hindbrain boundary, i.e., the midbrain-r0 boundary, thus suggesting that the Pax6-free region observed caudally to the midbrain-hindbrain boundary may represent the isthmus or $\mathrm{r} 0$ hindbrain division (Figures $1 \mathrm{H}$ and $3 \mathrm{~A}$ ). The anterior limit of the rhombencephalic expression of Pax6 in S. canicula does not overlap with the FGF8 expression domain that, as in other vertebrates, largely corresponds to the isthmus (unpublished observations). Accordingly, the anterior limit of the rhombencephalic Pax6-positive domain roughly coincides with the $\mathrm{r} 0-\mathrm{r} 1$ boundary. In this region, there is a population of dorsoventrally oriented GABAergic cells, some of them being DCX positive (Figures 3B-F).

The segmental organization of the elasmobranch rhombencephalon has been considered peculiar in relation to the exit of the trigeminal (V) nerve root. In the late pharyngula stage of S. torazame and other elasmobranch species (Kuratani and Horigome, 2000; Gilland and Baker, 2005; and references therein), the V nerve root has been described located in $\mathrm{r} 3$, close to the "acoustic-facial" (VII-VIII) nerve roots fixed in $\mathrm{r} 4$ (Figures 2 and 4A-D), instead than in $\mathrm{r} 2$ as in other vertebrates (reviewed by Gilland and Baker, 2005). It has been argued that the unusual localization of the dogfish $\mathrm{V}$ nerve root is acquired secondarily because it appears to enter in $\mathrm{r} 2$ in early pharyngula stages of $S$. torazame (Kuratani

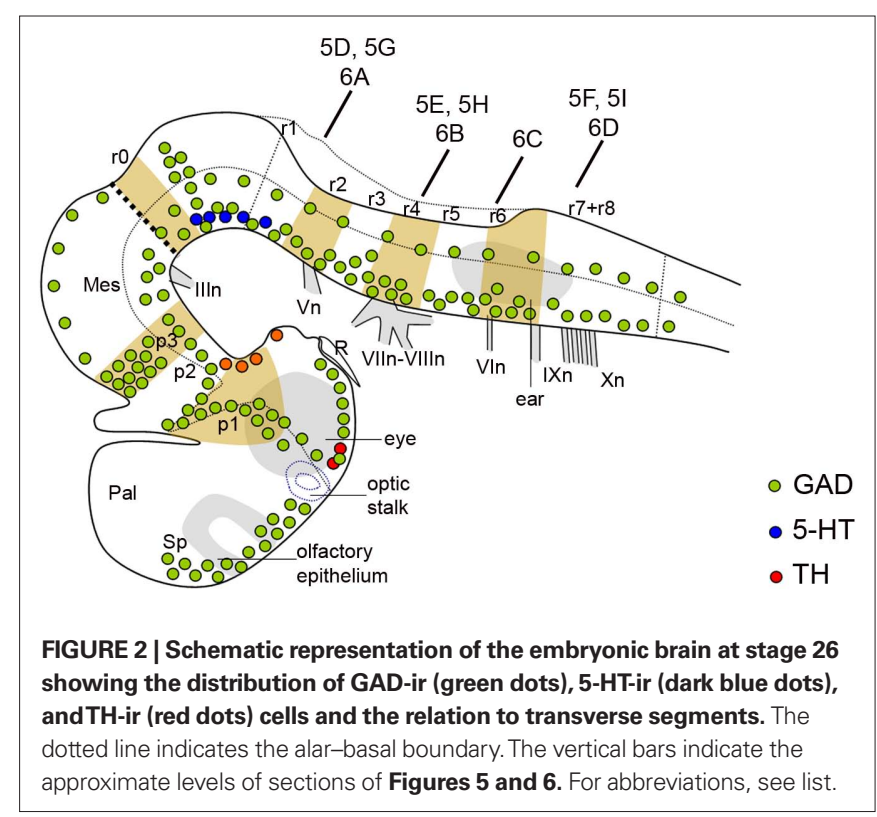



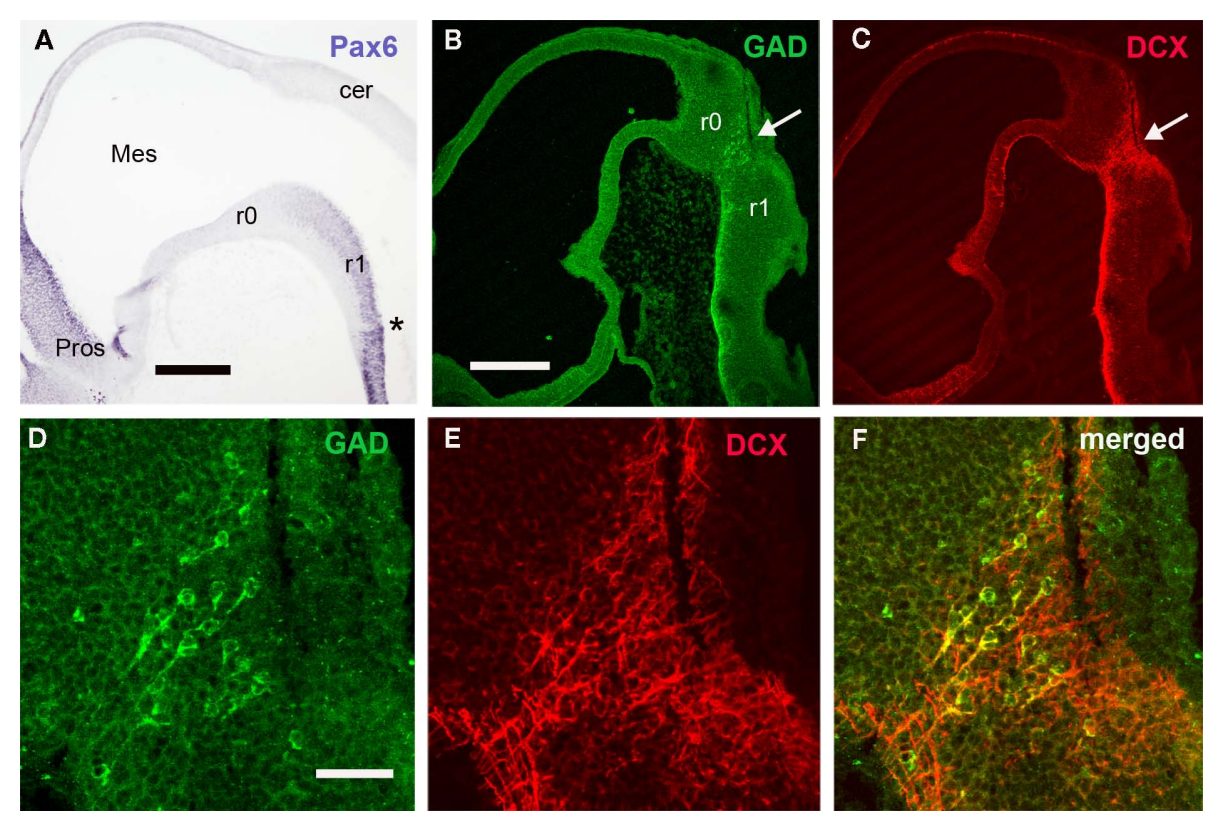

FIGURE 3 |The distribution of Pax6, GAD, and DCX cells reveals the r0/r1 boundary. (A-C) Panoramic views of sagittal sections of embryos at stage 26 to show the distribution of Pax6 (A), GAD (B), and DCX (C) in the rostral rhombencephalon. Note the absence of Pax6 cells in $\mathrm{r} 0$ and the dorsoventral band of GAD and DCX cells caudally to rO (white arrow in B,C). (D,E) Detail of this cell band to show colocalization of both substances in some cells (yellow in F). Asterisk in $A$ indicates the rostralmost intrarhombomeric boundary at $r 1$. For abbreviations, see list. Scale bars: $500 \mu \mathrm{m}$ (A); $300 \mu \mathrm{m}$ (B,C); $50 \mu \mathrm{m}$ (D-F) and Horigome, 2000). According this hypothesis, the late caudal location of the $\mathrm{V}$ nerve root is originated by a caudal shift of the trigeminal neural crest that arises initially from r2 (Neal, 1898; Kuratani and Horigome, 2000). However, since both the established nerve roots and the interrhombomeric boundaries are held to be fixed structural entities, incapable of active movement, this hypothesis of a caudally shifting root does not seem convincing. The massiveness of the $\mathrm{V}$ nerve root discards the possibility of a substitution of a new $\mathrm{r} 3$ trigeminal root for a disappearing $\mathrm{r} 2$ root (as conjectured above for the very slender glossopharyngeal and vagal roots). Our observations at later stages reveal that there is a root-less part of the hindbrain wall intercalated between the $\mathrm{V}$ and VII-VIII roots (Figures 1C,E,H; see also Figure 4C), which represents a possibly compressed $\mathrm{r} 3$. In any case the $\mathrm{V}$ root would actually lie in r2. Our results also suggest that, in dogfishes, an intrarhombomeric ventricular ridge develops rostral to the $\mathrm{r} 1 /$ r2 limit between early and late pharyngula stages, possibly due to large growth of this region. As noted above in relation to the HoxA2 results, there is a conspicuous ventricular ridge into $\mathrm{r} 1$ (asterisks in Figures 1A-D) that appears to subdivide this large rhombomere in a caudal region with an appearance of rhombomere and a more rostral one showing a different appearance (note in Figure 1H the maintaining of correspondence of proposed rhombomeres $\mathrm{r} 2$ and $\mathrm{r} 4$ with branchial arches). The $\mathrm{r} 1$ territory is noticeably larger than a normal rhombomere in all vertebrates, and Vaage $(1969,1973)$ already suggested that it may contain a cryptic subdivision into rostral and caudal parts in some vertebrates. The formation in S. canicula of an additional boundary rostral to the normal $\mathrm{r} 1 / \mathrm{r} 2$ limit actually may explain the surprising "displacement" of the V nerve root exit claimed by some authors (Neal, 1898;
Kuratani and Horigome, 2000). The solely use of morphology to assign rhombomeres based on von Kupffer (1906), which defined rhombomere 1 as the anterior region of the hindbrain between the meso-rhombencephalic border and the first distinct hindbrain interneuromeric border, would result in $\mathrm{r} 2$ to be counted as $\mathrm{r} 3$ in previous studies (and r3 $+\mathrm{r} 4$ to be identified as $\mathrm{r} 4$ ).

The identification of the caudal rhombomeres and the limit between the rhombencephalon and the spinal cord in S. canicula are unclear. Caudally to the conspicuous $\mathrm{r} 5 / \mathrm{r} 6$ boundary there is a subtle ventricular ridge that could correspond to the $\mathrm{r} 6 / \mathrm{r} 7$ boundary but there are not more evidences of intraventricular ridges, which preclude identification of $r 7$ and $r 8$ on the basis of such interrhombomeric limits. The position of the abducens (VI), glossopharyngeal (IX), and vagal (X) nerve roots may help to identify the caudal rhombomeres. In early embryos of $S$. canicula (S26) the root of the abducens nerve was located in r6 (Figures 2 and 4E), in agreement with the location of abducens motoneurons reported in adults of this species by ChAT immunohistochemistry (Anadón et al., 2000), and by tract-tracing methods in Squalus embryos (Gilland and Baker, 1992). The IX and $\mathrm{X}$ nerve roots emerge from the non-segmented region caudal to $\mathrm{r} 6$ that supposedly consists of r7 and r8 but, without specific molecular markers, their position in relation to rhombomeres could not be assessed. Even so, the IX nerve root emerges close to the r6-r7 border and the first X nerve root emerges somewhat caudally (Figure 2). In late pharyngula stages of the sharks Squalus acanthias (Scammon stages 24-26; Gilland and Baker, 1992, 1993, 2005) and S. torazame (stage V; Kuratani and Horigome, 2000) the emergence of IX and X roots has been established in $\mathrm{r} 7$ and r8, respectively (Gilland and Baker, 1992, 1993, 2005; Kuratani 

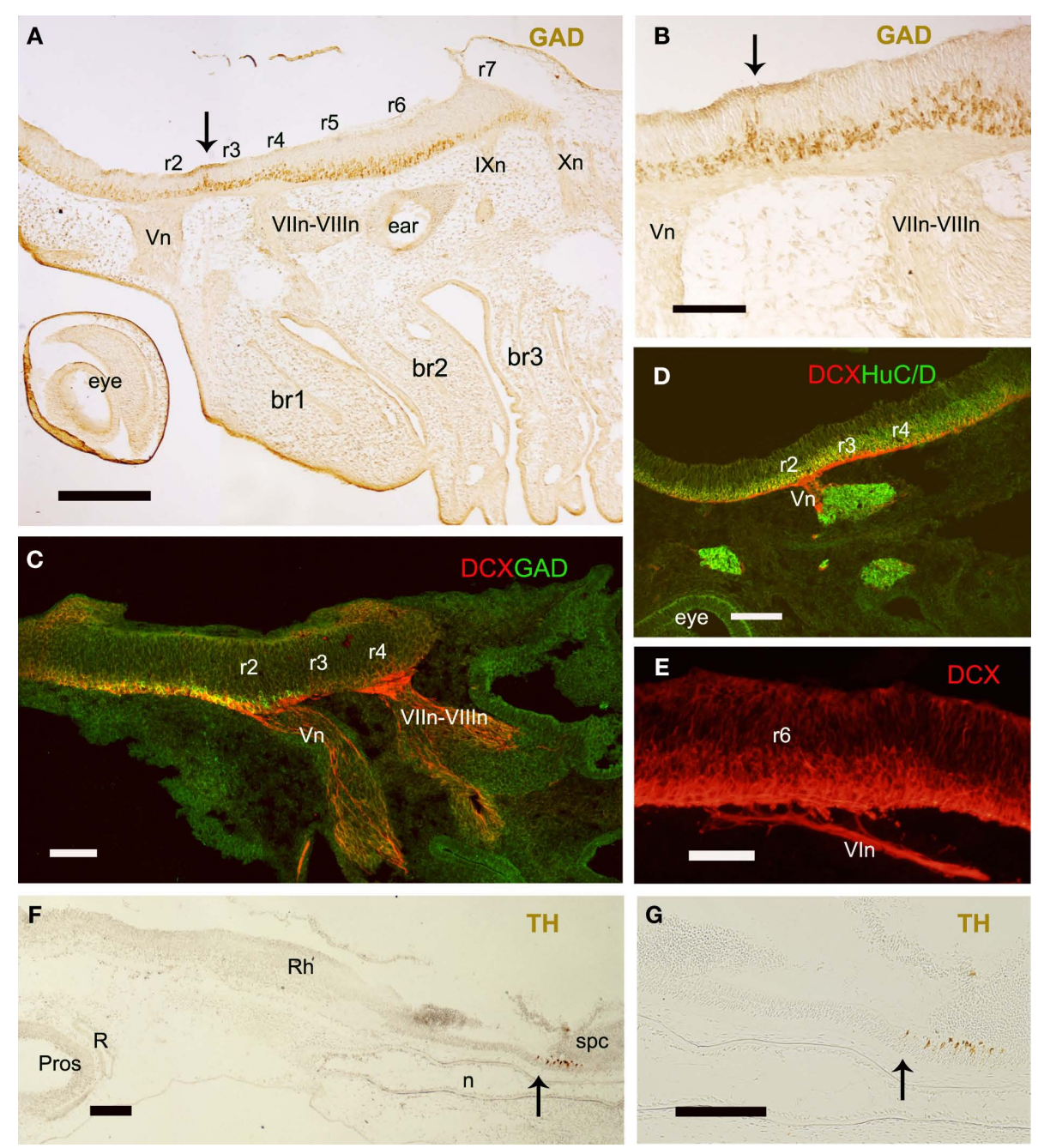

FIGURE 4 | Sagittal sections of embryos at stage 26 to show the position of nerve roots in relation to rhombomeres $(A-E)$ and the caudal limit of the rhombencephalon (F,G). (A,B) Panoramic view and detail to show the roots of several branchiomeric nerves and the distribution of GAD-ir cells at the $r 2-r 3$ interrhombomeric boundary (arrows). (C-E) DCX labeled processes at the roots of $\mathrm{V}(\mathbf{C}, \mathbf{D}), \mathrm{VII}-\mathrm{VIII}$ (C), and VI (E) nerves. (F,G) Panoramic view and detail showing the rostral extension of the spinal TH-ir CSF-contacting neurons. Arrows indicate the possible rhombencephalon-spinal cord boundary. For abbreviations, see list. Scale bars: $200 \mu \mathrm{m}(\mathbf{A}, \mathbf{C}, \mathbf{D}, \mathbf{F}, \mathbf{G}) ; 100 \mu \mathrm{m}$ (B,E).

VII, IX, and X motoneurons has been reported (Chandrasekhar et al., 1997). The use of molecular markers appears necessary to decipher unequivocally the segmental organization of the caudal rhombencephalon in S. canicula.

The spinal floor plate in S. canicula shows characteristic GABAergic and catecholaminergic cerebrospinal fluid (CSF)-contacting cells, which by contrast are absent from the rhombencephalic floor plate (Sueiro et al., 2003, 2004). A re-analysis of these results reveals that the rostral most CSF-contacting cell populations of the floor plate are located at a level just caudal to the last $\mathrm{X}$ nerve root. We suggest to use this level as reference for the rhombencephalon-spinal cord boundary (Figures 4F,G). However, in chicken this limit was traced at the middle level of the 5 th somite owing the existence of additional rhombomere-like regions (pseudorhombomeres; Cambronero and Puelles, 2000; Marín et al., 2008), which is more caudal than that proposed for $S$. canicula. Whether pseudorhombomeres also exist in dogfish need be investigated. 


\section{Longitudinal columns}

Here we also explored the longitudinal organization in the early rhombencephalon of $S$. canicula. At the earlier stages of $S$. canicula studied, longitudinal ventricular sulci are not evident and specific molecular markers for the alar-basal boundary have not been tested. However, the existence of rhombencephalic longitudinal zones, and the boundary between alar and basal plates can be roughly identified on the basis of the columnar distribution of Pax6- and GAD-positive cells.

At early stages, Pax6-labeled cells formed a column continuous with that of the spinal cord. They occupied the majority of the rhombencephalic lateral wall excepting the floor plate and the adjacent region of the basal plate, as inferred from the comparison with parallel sections immunostained for sonic hedgehog (Shh), a well known hindbrain floor plate marker in other vertebrates (Figures 5A-I). However, differences in the intensity of Pax6 expression allowed us to distinguish between a ventrolateral column that contained the most intensely labeled Pax6 cells and coincided in part with the extent of the basal plate (excepting the negative region adjacent to the floor plate), and a dorsolateral alar column containing weakly labeled Pax6 cells. At the level of VIIVIII nerve roots $(\mathrm{r} 4)$, this dorsolateral column extended dorsally up to the developing roof plate choroid plexus, thus probably corresponding with the full extent of the alar plate. Rostrally, the dorsal rhombencephalic region that gives rise to the cerebellar primordium (cerebellar plate) did not contain Pax6 cells (Figure 1H).
At stage 26, the GAD-immunoreactive (ir) populations appeared clearly organized in longitudinal columns extending all along the rhombencephalon (Figure 6). Sagittal (Figures 6B-D) and transverse (Figures 6E-H) sections revealed two main bands of GAD-ir cells located in the mantle layer; one was dorsolateral (in the alar plate; open arrow in Figures $\mathbf{6 B}-\mathbf{H}$ ) and the other was ventrolateral (in the basal plate; solid arrow in Figures 6B-H), and they were separated by a band of GAD-negative cells (asterisks in Figures 6C-H). Ventral commissural axons that mainly emerged from cells of the ventrolateral group were observed throughout the rhombencephalon. From the level of the "acoustic-facial" (VIIVIII) nerve roots ( $\mathrm{r} 4$ ) down to caudal rhombencephalic levels, the dorsolateral and ventrolateral columns each appeared subdivided into dorsal and ventral sub-columns (Figures 6F-H). The ventrolateral columns were continuous with those observed in the rostral spinal cord (Sueiro et al., 2004). In contrast with what was observed in the spinal cord (Sueiro et al., 2004), no CSF-contacting GAD-ir cells were present in the hindbrain floor plate.

\section{REGIONALIZATION OF THE HINDBRAIN IN INTERMEDIATE EMBRYOS (SECOND PERIOD) Longitudinal columns}

In intermediate embryo stages, the Pax6-ir cells also formed longitudinal columns in the dorsal, laterodorsal (alar plate) and lateroventral (basal plate) rhombencephalic walls. Pax6 expression in
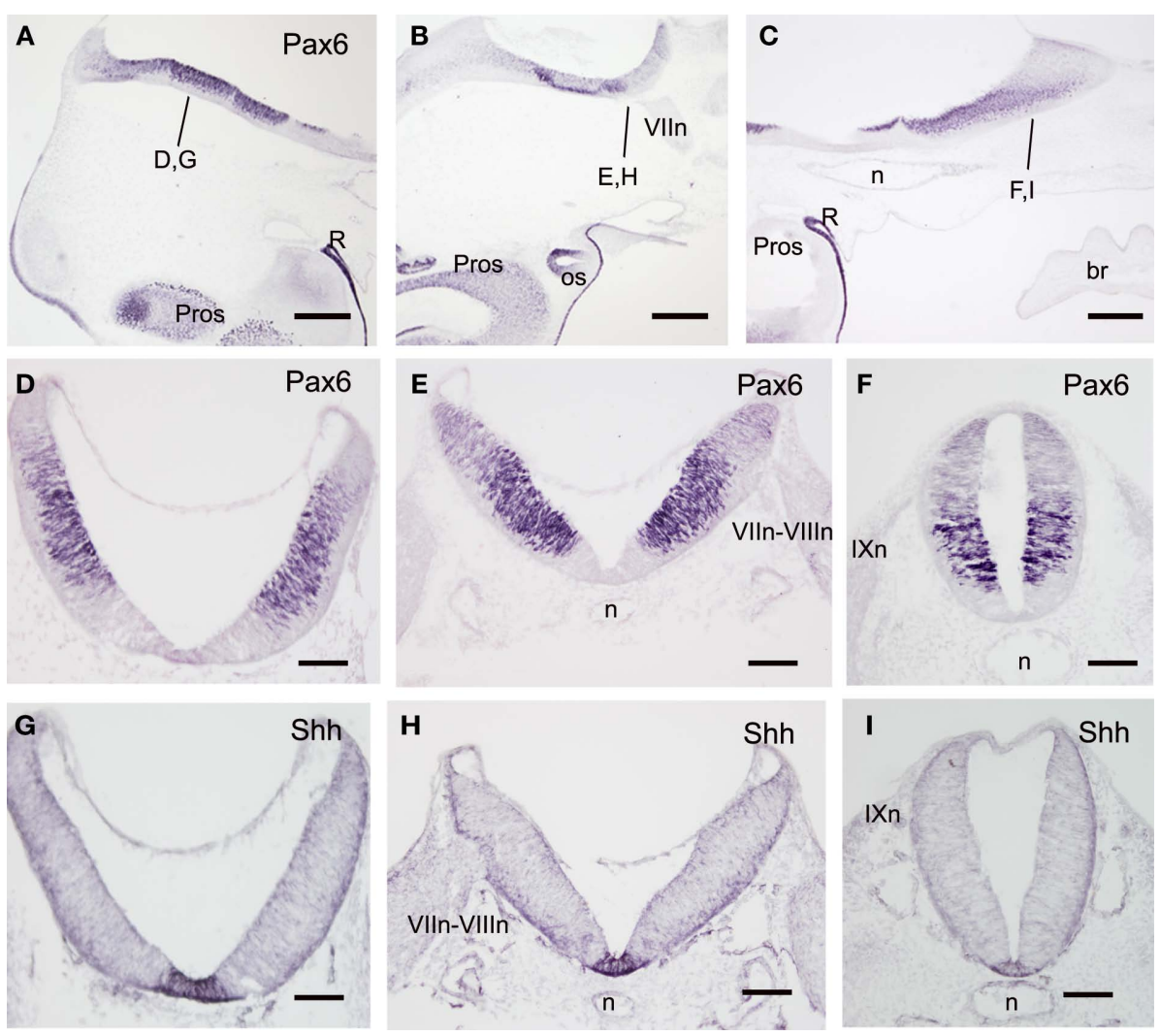

FIGURE 5 | Sagittal (A-C) and transverse (D-I) sections of embryos at stage 25 to show the distribution of Pax6- (A-F) and Sonic hedgehogimmunoreactive cells (G-I). The levels of (D-I) are indicated in (A-C) and in Figure 2. Scale bars: $500 \mu \mathrm{m}$ (A-C); $200 \mu \mathrm{m}$ (D-I) 


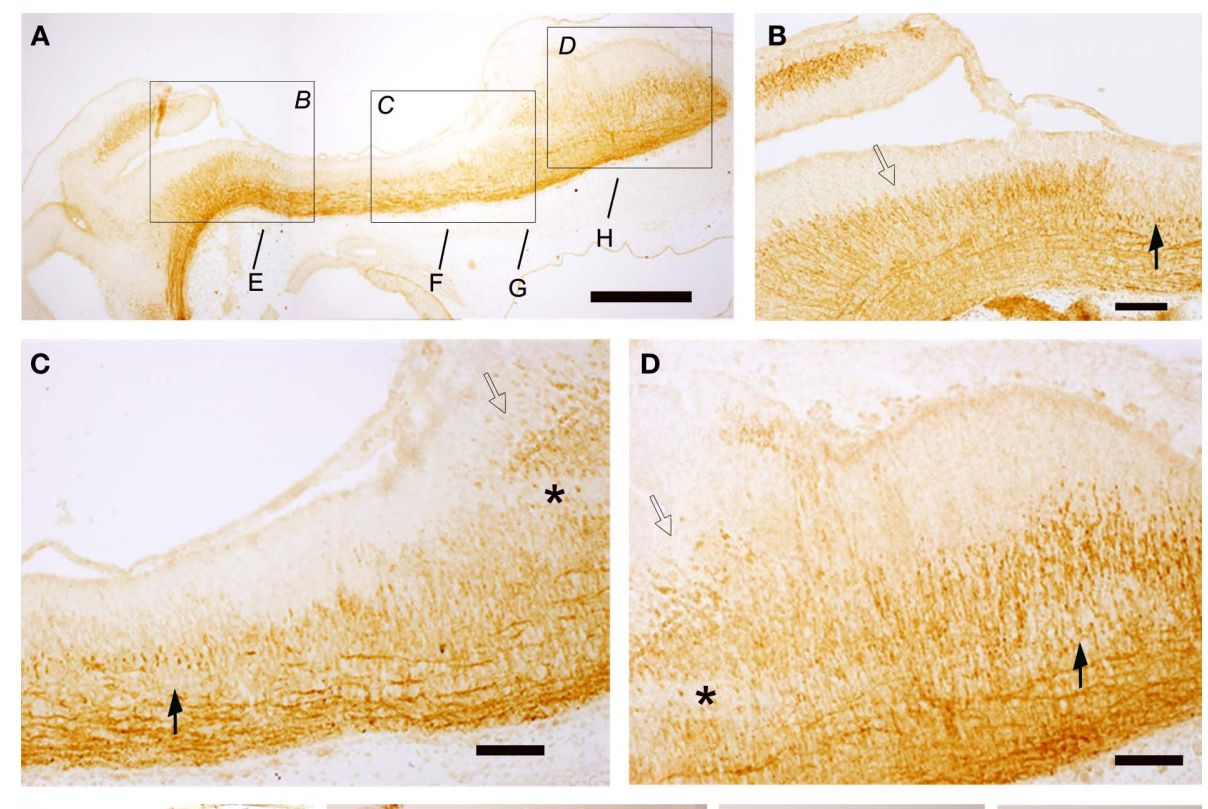

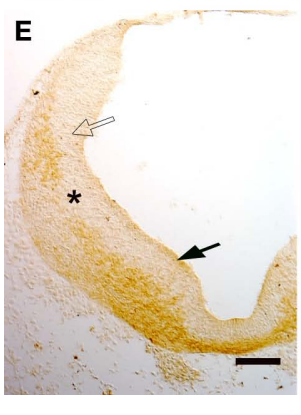

FIGURE 6 | Sagittal (A-D) and transverse (E-H) sections of embryos at stage 26 showing the columnar distribution of GAD-ir populations. The levels of (E-I) are indicated in (A) and in Figure 2. Dorsolateral and ventrolateral columns are continuous along the rhombencephalon from rostral to caudal levels (A-H) but from $\mathrm{r} 4$ these columns appeared subdivided into dorsal and ventral subgroups (F-H). Scale bars: $500 \mu \mathrm{m}$ (A); $100 \mu \mathrm{m}$ (B-H). the ventricular zone decreased, being reduced to the dorsal portion of the alar and basal plates, i.e., the dorsal and lateroventral wall sectors (Figures 7A-D), although rostrally the decrease in immunoreactivity of dorsal cells was less evident.

With regard to GAD-ir longitudinal cell columns, they were more evident than in the previously studied stage, and four longitudinal columns were clearly distinguished along most of the rhombencephalon. These four longitudinal GABAergic columns were located respectively in the four classic functional columns: somatosensory, viscerosensory, visceromotor, and somatomotor (Figures 7F-H). However, at rostral levels (r1-r2) only two main columns were noted (Figure 7E).

There was no obvious overlap between Pax6-ir and GABAergic cell columns, which were located in the ventricular and mantle zones, respectively. However, double labeling revealed a correlation between the sharp limit separating the intensely and weakly Pax6-ir ventricular cells, and the limit between the dorsolateral and ventrolateral GAD columns (Figures 7I-O). This limit may represent the alar-basal boundary.

No CR-ir cells were observed in S. canicula embryos at early stages, but from the intermediate stage (S29) onward, CR-ir populations were noticed in different brain areas (Figure 8). At stage
29, CR-ir cells were observed in all brain vesicles but were more abundant in the posterior brain (Figure 8). These cells were scarce at alar prosencephalic (subpallium and thalamus) and mesencephalic (optic tectum) levels and moderately abundant in the basal diencephalon (posterior tubercle and basal synencephalon, where formed the primordium of the nucleus of the medial longitudinal fascicle). In contrast, the rhombencephalon contained abundant CR-ir cells along the whole extension of alar and basal regions. To identify all the rhombencephalic CR-ir cell groups exceeds the aims of this study, as they develop on later stages. However, the apparent columnar organization of rhombencephalic CR-ir populations in an intermediate stage (S29) makes CR a very suitable marker to analyze the longitudinal columnar organization both in alar and basal territories (Figure 9).

In the basal rhombencephalon, CR-ir cells formed an almost continuous column from isthmic to spinal levels (Figures 9A-J). Most of them form part of the reticular formation, which contains raphe (midline) populations organized as a continuous field in the superior reticular formation $(\mathrm{r} 1-\mathrm{r} 4)$ and more lateral reticular populations that extended down to caudal rhombencephalic levels (Figures 9B-I). Other basal CR-ir populations identified at this intermediate stage were the visceromotor nuclei (Figures 9D,E,I,J). 

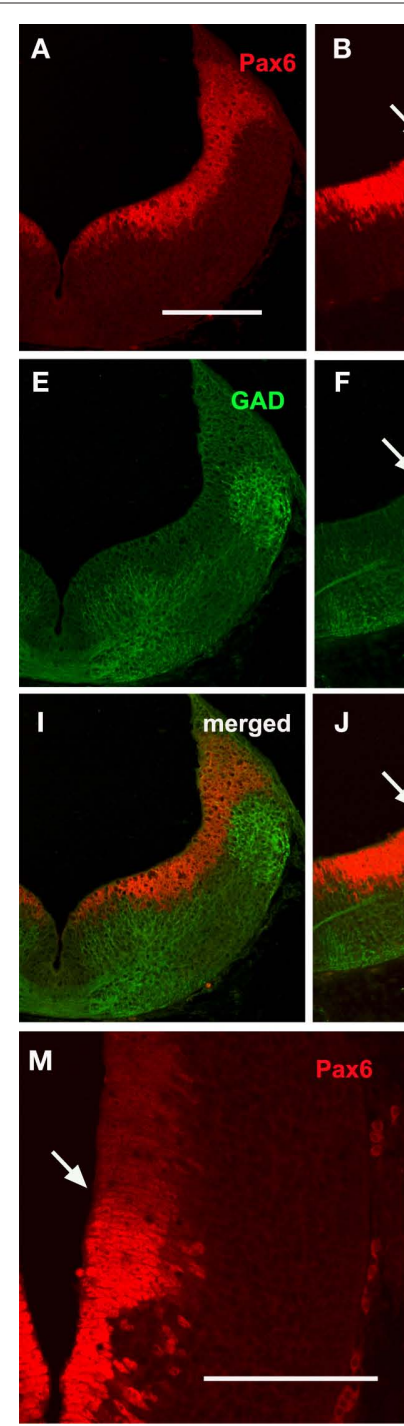

FIGURE 7 |Transverse sections from rostral $(A, E, I)$ to caudal $(D, H, L)$ rhombencephalic levels of embryos at stage 29 showing the comparative distribution of Pax6 (A-D) and GAD (E-H) cells. Double labeling (I-L) reveals a
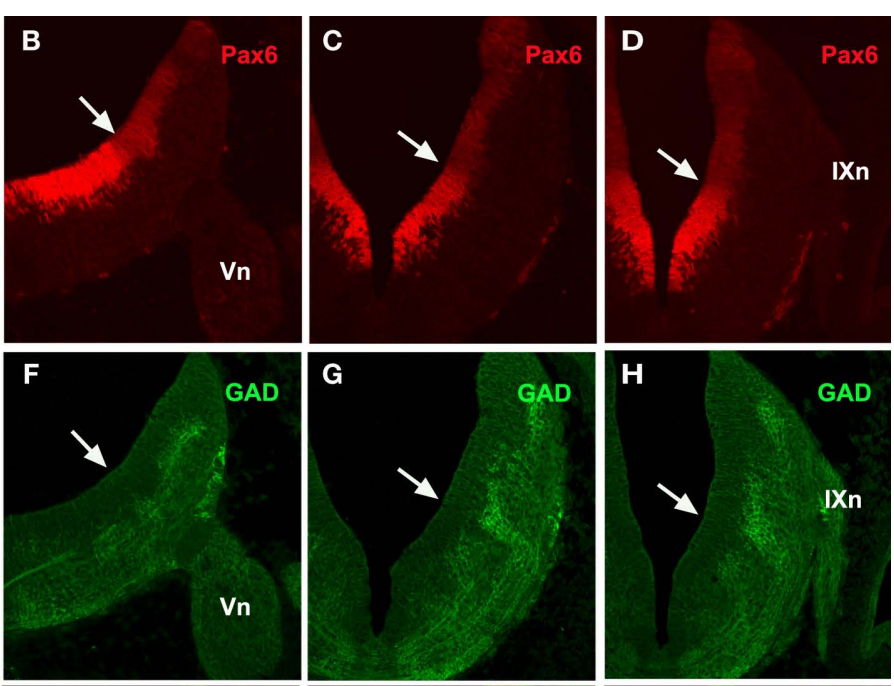

G
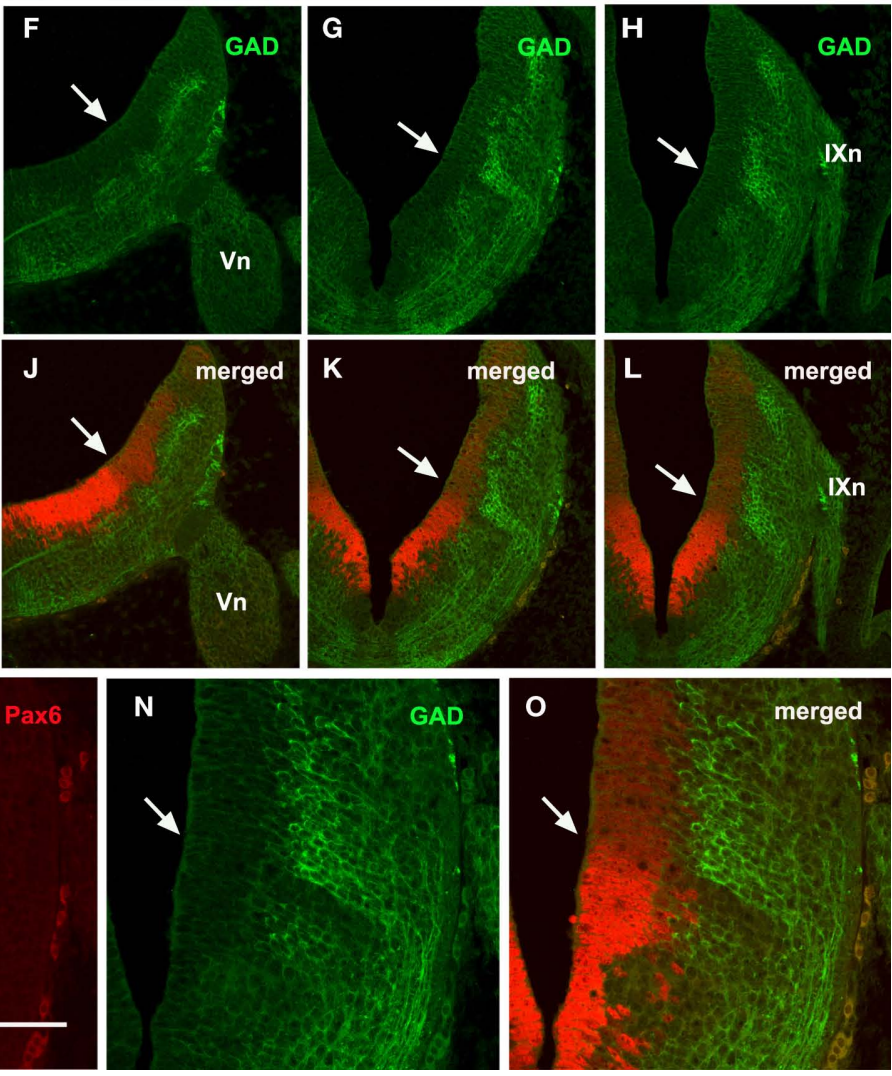

band of GAD-negative cells coinciding with the interface between intense and weak Pax6 cells that may corresponds to the alar-basal boundary (white arrows). (M-O) Detail of this boundary. Scale bar: $200 \mu \mathrm{m}$ (A-L); $100 \mu \mathrm{m}$ (M-O).
At isthmic levels, some small CR-ir cells were located medially, probably forming part of the primordial interpeduncular nucleus (not shown). At caudal rhombencephalic levels (at the level of entrance of the X nerve roots), some weakly CR-ir cells were found ventrally to the medial longitudinal fascicle, which at these levels contained moderately labeled fibers. This caudal CR-ir population of the basal rhombencephalon probably corresponds to the inferior olive primordium (Figures 8 and 9E, J).

In the rhombencephalic alar plate, no CR-ir cells were observed at the intermediate stage (S29) in the cerebellar plate (Figure 9A) but later in development, abundant cells were found in the molecular layer of the cerebellar body and related cerebellar-like structures (Rodríguez-Moldes et al., 2008; Anadón et al., 2009). Moreover, CR-ir cells were observed along the alar dorsolateral column from rostral to caudal rhombencephalic levels. Along its extent, different subgroups could be distinguished. A dorsolateral population containing large CR-ir cells intermingled with smaller elements extended from $\mathrm{r} 2$ to $\mathrm{r} 6$, and probably represents primordial nuclei of the octavolateral area (Figures 9G,H). Another subgroup of the dorsolateral column contained few small weakly labeled CR-ir cells that occupied the ventricular protrusion that extended from 4 to 8 and represents cells of the primordial viscerosensory lobe (Figures 9G-J).

\section{Transverse segmental regions}

At the intermediate stage (S29), the interrhombomeric boundaries become blurred and are no longer detectable morphologically. In spite of this, the transversal organization in rhombomeres 1 to 8 of the $S$. canicula rhombencephalon may be inferred on the basis of the position of (a) the nerve roots, as their relationship with rhombomeres does not change with respect to earlier stages and (b) the reticular cells, motoneurons and other 


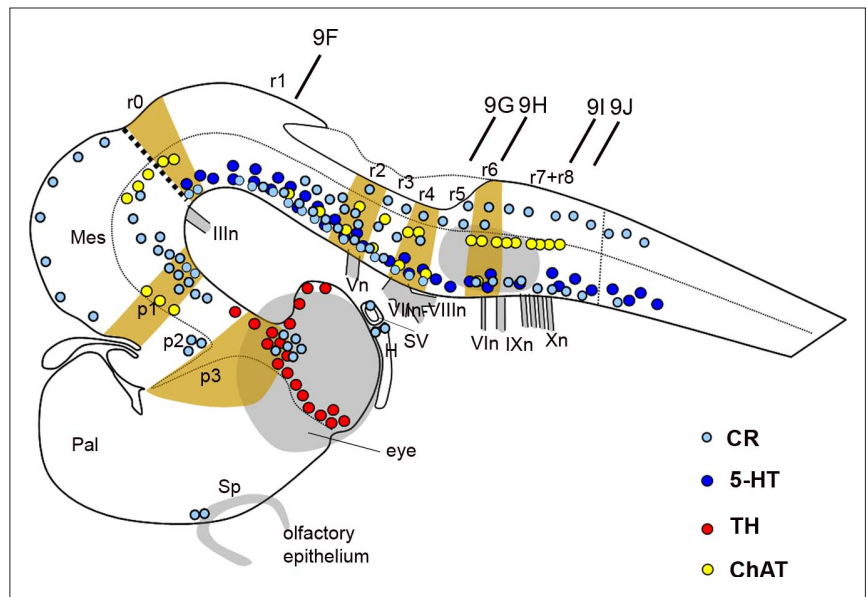

FIGURE 8 | Schematic representation of the embryonic brain at stage 29 showing the distribution of CR- (bright blue dots), 5-HT- (dark blue dots), TH- (red dots), and ChAT-ir (yellow dots) immunoreactive cells and the relation to transverse segments. The dotted line indicates the alar-basal boundary. The vertical bars indicate the approximate levels of sections of Figure 9. For abbreviations, see list.

rhombencephalic populations which are distributed following a segmental organization. A segmental organization can also be revealed by using antibodies raised against TH, 5-HT, and ChAT, which label catecholaminergic, serotoninergic, and cholinergic populations, respectively, and against CR. Accordingly, we studied the possible extent of rhombomeres in the hindbrain of S. canicula S29 embryos by identifying conspicuous chemoarchitectonic boundaries (Figure 8).

A previous work has reported the development of catecholaminergic (TH-ir) populations in the embryonic brain of S. canicula (Carrera et al., 2005). Although TH-ir cells were already present in the hypothalamus and diencephalon by stage 29 (Figure 8), in the rhombencephalon $\mathrm{TH}$-ir cells started to appear at stages 30-31 (Carrera et al., 2005). Here, we briefly re-examined the rhombencephalic catecholaminergic populations in the context of the rhombomere organization raised by analysis of HoxA2 and Wnt 8 genes (see above). From stage 30 onward, the rostral rhombencephalic TH-ir groups, i.e., the locus coeruleus (rostral) and subcoeruleus (caudal) were recognized as located at $\mathrm{r} 1$ and r2, respectively (not shown in Figure 8, as it represents the stage 29). They occupied dorsal territories of the basal region since the first time in which became detectable by TH immunohistochemistry (although in chick and mouse they originate from the alar plate; Aroca et al., 2006). Caudal rhombencephalic TH-ir cell groups were related to alar (viscerosensory column) and basal (visceromotor column and reticular cells) regions. Populations of the viscerosensory and visceromotor columns extended from a level caudal to the entrance of the VII-VIII nerves down to the obex, i.e., from $\mathrm{r} 5$ to $\mathrm{r} 8$, while the ventrolateral reticular TH-ir cells extended from levels of the VI motor nucleus to the obex, occupying therefore r6-r8.

The development of serotoninergic populations in S. canicula has been previously described (Carrera et al., 2008). All serotoninergic (5-HT-ir) cell groups of the adult rhombencephalon were already differentiated at stage 29 but not those of more rostral brain levels
(Carrera et al., 2008), which is in sharp contrast to that happens with catecholaminergic populations (Figure 8). In the rhombencephalon, serotoninergic cells occupied basal reticular territories and formed midline (raphe) and lateral (reticular) populations, both arising from cells adjacent to the floor plate (Carrera et al., 2008). The reticular 5-HT-ir cell groups exhibited a clear segmental pattern, which allowed to correlate them with rhombomeres. In the study of Carrera et al. (2008), the description of hindbrain populations followed the rhombomere numeration proposed by Neal (1898) and others (Gilland and Baker, 1993, 2005; Kuratani and Horigome, 2000). After re-examining the results of Carrera et al. (2008) at the light of the present rhombomeric numeration, we confirm that the mid/hindbrain boundary coincides approximately with the rostral end of three 5-HT-ir nuclei (raphe linearis, raphe dorsalis anterioris, and reticular B9 cell group) but disagree with our previous interpretation in the $\mathrm{r} 1 / \mathrm{r} 2$ and $\mathrm{r} 2 / \mathrm{r} 3$ location. Under the present view, the $\mathrm{r} 1 / \mathrm{r} 2$ boundary actually coincides with the caudal end of three reticular 5-HT-ir nuclei (subcoeruleus, raphe pontis oralis medialis, and lateralis) and the rostral end of the raphe dorsalis, while the $\mathrm{r} 2 / \mathrm{r} 3$ boundary corresponds to the raphe dorsalis caudal end. There were no 5-HT-ir neurons between levels caudal to the $\mathrm{V}$ motor nucleus and rostral to the facial nerve root, which may correspond at some extent to $\mathrm{r} 3$ levels. This rhombomere also marks the separation between the superior and inferior sets of 5-HT-ir nuclei.

The segmental organization of the motor nuclei has been reported in adult S. canicula by using ChAT as a marker for cholinergic neurons (Anadón et al., 2000). The same marker is used in the present study to identify motor nuclei in the rhombencephalon of S29 embryos (Figures 8 and 10). The rhombomere distribution of some motor nuclei of S29 embryos varied in relation to what was described in adults although, owing the change in numeration of rhombomeres. The ChAT-ir trochlear cells were located in the basal region of the isthmus ( $\mathrm{r} 0$ ), separated by a clear-cut gap from the ChAT-ir oculomotor cells, which were located just rostrally in the mesencephalic tegmentum (Figures 10A,B). The ChAT-ir cells located at the level of the V nerve root probably correspond to the $\mathrm{V}$ motor nucleus, which is located in $\mathrm{r} 2$, and not in $\mathrm{r} 3$ as previously described (Anadón et al., 2000). The rostral end of this motor nucleus roughly coincides with the $\mathrm{r} 1 / \mathrm{r} 2$ boundary (Figures 10A,C). The large ChAT-ir cell aggregate at the level of the VII-VIII nerve roots corresponds to the magnocellular octaval nucleus, which extended in $\mathrm{r} 4$ and the caudal part of r3 (Figures 10A,D,E). In r6, the group of labeled cells located at ventral levels probably corresponds to the VI nucleus. The cholinergic neurons of the visceromotor column were distinguished more dorsally, forming a column that extended along r6 and r7 (Figures 10E,F). The presence of some rostrocaudal discontinuities revealed the existence of three ChAT-ir cell clusters; the rostralmost probably represents the facial motor nucleus (located just rostral to the level of entrance of the IX nerve), while the groups that correspond to IX and X nuclei were located more caudally, just ventral to the viscerosensory lobe, where the roots of IX and X nerves were clearly discerned (Figure 10E,F). This observation reveals that in S. canicula intermediate embryos the facial motor nucleus is located in the same segment as in the adult (Anadón et al., 2000). Studies in embryos with earlier markers 


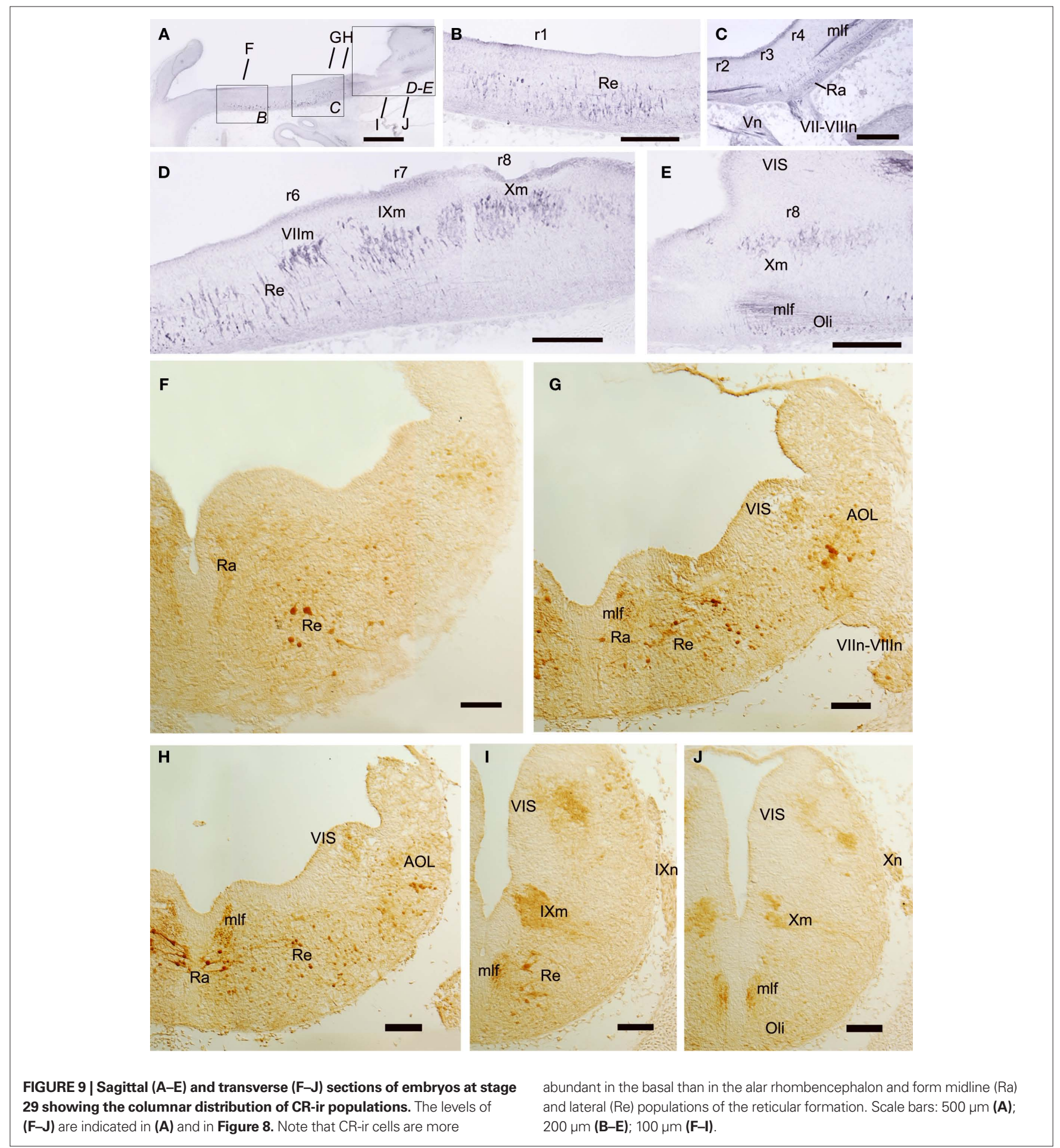

of these motor populations are necessary in order to know if these cells originate from this rhombomere or from more rostral rhombomeres (r4-r5) and then migrate caudally, as it has been described in Squalus (Gilland and Baker, 1992) and in zebrafish (Chandrasekhar et al., 1997).

The columns of CR-ir cells along the alar and basal plates present some discontinuities that revealed the existence of clusters roughly related to rhombomeres. Raphe (midline) CR-ir cells formed two major groups; one extends along r $1-\mathrm{r} 2$ and contained small weakly labeled cells (Figure 9F) while the other occupies r3-r4 and contained large intensely labeled cells with their processes oriented mainly mediolaterally, some of them crossing the midline (Figures 9C,G,H). Reticular (lateral) cells were scarce in the rostral part of $\mathrm{r} 1$, but more caudally they formed a relatively abundant population of large cells that extended from the caudal part of r1-r4 (Figures 9B,C,F,G). In r5 and r6, CR-ir reticular cells 

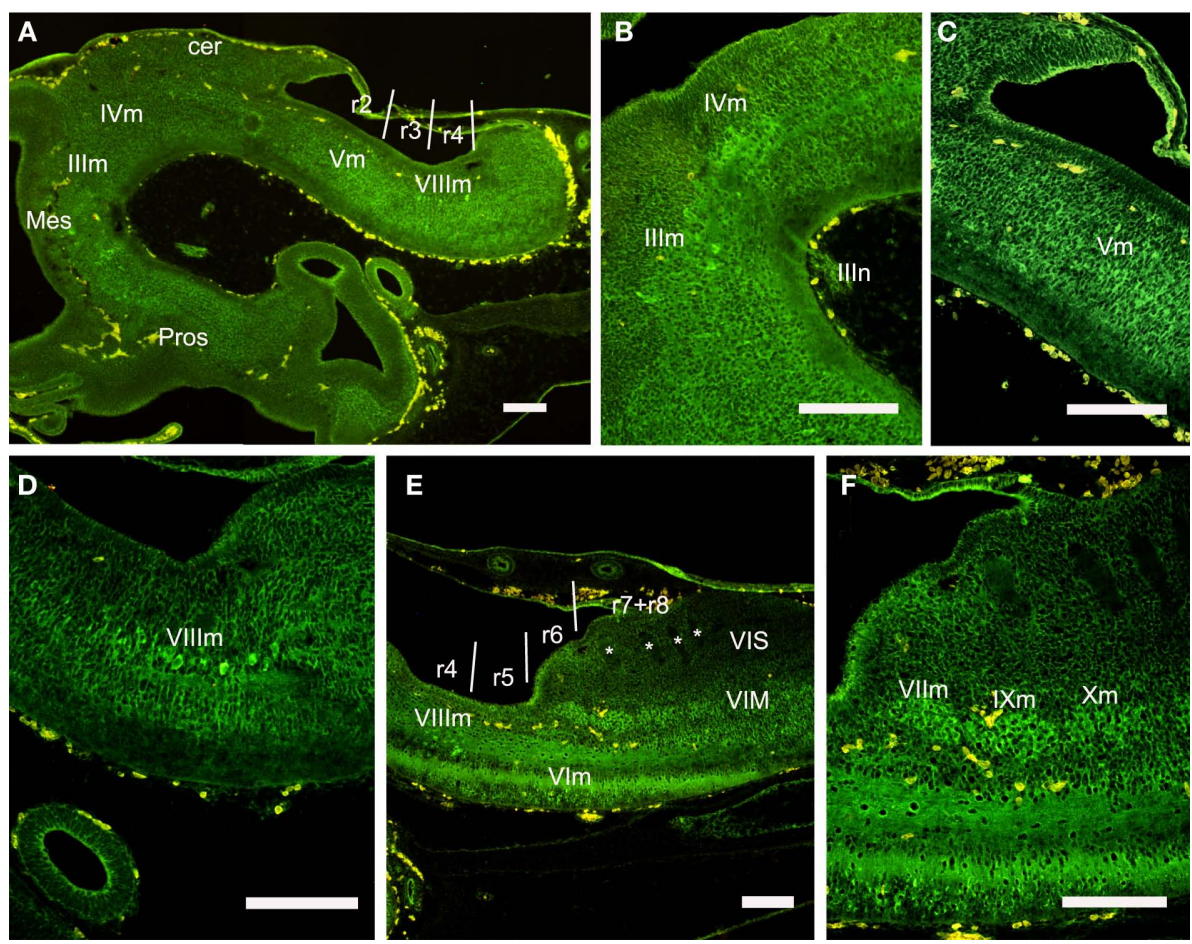

FIGURE 10 | Sagittal sections showing the distribution of ChAT-ir cell groups in the rhombencephalon at the stage 29. (A-D) Panoramic view (A) and details (B-D) of ChAT-ir cells of the oculomotor and trochlear nucleus (B), trigeminal motor nucleus (C), and magnocellular octaval nucleus (D). (E,F) Panoramic view and detail of ChAT-ir cells in the visceromotor column. Asterisks label the negative roots of the glossopharyngeal and vagal nerves. For abbreviations, see list. Scale bars: $200 \mu \mathrm{m}$.

were small and scarce (Figure 9D,H), while large reticular CR-ir cells were present in the putative r7 (Figure 9I). More caudally the small weakly labeled cells of the inferior olive were observed (Figures 9E,J).

Although the molecular markers used in this study reveal some interesting features in the embryonic brain of the lesser spotted dogfish, further studies are necessary to give a more precise account of the rhombomeric limits and rhombomere identities, specially in the caudal rhombencephalon.

\section{REFERENCES}

Alexander, T., Nolte, C., and Krumlauf, R. (2009). Hox genes and segmentation of the hindbrain and axial skeleton. Annu. Rev. Cell Dev. Biol. 25, 431-456.

Anadón, R., Ferreiro-Galve, S., Sueiro, C., Graña, P., Carrera, I., Yañez, J., and Rodríguez-Moldes, I. (2009). Calretinin-immunoreactive systems in the cerebellum and cerebellumrelated lateral-line medullary nuclei of an elasmobranch, Scyliorhinus canicula. J. Chem. Neuroanat. 37, 46-54.

Anadón, R., Molist, P., Rodríguez-Moldes, I., López, J. M., Quintela, I., Cerviño, M. C., Barja, P., and González, A. (2000). Distribution of choline acetyltransferase immunoreactivity in the brain of an elasmobranch, the lesser spotted dogfish (Scyliorhinus canicula). J. Comp. Neurol. 420, 139-170.

Aroca, P., Lorente-Cánovas, B., Mateos, F. R., and Puelles, L. (2006). Locus coeruleus neurons originate in alar rhombomere 1 and migrate into the basal plate: studies in chick and mouse embryos. J. Comp. Neurol.496, 802-818.

Aroca, P., and Puelles, L. (2005). Postulated boundaries and differential fate in the developing rostral hindbrain. Brain Res. Rev. 49, 179-190.

Ballard, W. W., Mellinger, J., and Lechenault, H. (1993). A series on normal stages for development of Scyliorhinus canicula, the lesser spotted dogfish (Chondrichthyes: Scyliorhinidae). J. Exp. Zool. 267, 318-336.

\section{ACKNOWLEDGMENTS}

The present study was supported by grants of Spanish Dirección General de Investigación-FEDER (BFU2007-61154, BFU201015816) and of Xunta de Galicia (PGIDIT07PXIB200102PR; 10PXIB200051PR; INCITE09ENA200048ES). Authors also acknowledge the support of the European Community - Research Infrastructure Action under the FP7 "Capacities" Specific Programme (ASSEMBLE grant agreement no. 227799). The EST sequencing project was taken in charge by Génoscope, Evry, France.

Bouillet, P., Oulad-Abdelghani, M., Ward, S. J., Bronner, S., Chambon, P., and Dollé, P. (1996). A new mouse member of the Wnt gene family, $\mathrm{mWnt}-8$, is expressed during early embryogenesis and is ectopically induced by retinoic acid. Mech. Dev. 58, 141-152.

Briscoe, J., Pierani, A., Jessell, T. M., and Ericson, J. (2000). A homeodomain protein code specifies progenitor cell identity and neuronal fate in the ventral neural tube. Cell 101, 435-445.

Cambronero, F., and Puelles, L. (2000). Rostrocaudal nuclear relationships in the avian medulla oblongata: a fate map with quail chick chimeras. $J$. Comp. Neurol. 427, 522-545.

Carrera, I., Molist, P., Anadón, R., and Rodríguez-Moldes, I. (2008) Development of the serotoninergic system in the central nervous system of a shark, the lesser spotted dogfish Scyliorhinus canicula. J. Comp. Neurol. 511, 804-831.

Carrera, I., Sueiro, C., Molist, P., Ferreiro, S.,Adrio, F., Rodríguez, M.A.,Anadón, R., and Rodríguez-Moldes, I. (2005). Temporal and spatial organization of tyrosine hydroxylase-immunoreactive cell groups in the embryonic brain of an elasmobranch, the lesser-spotted dogfish Scyliorhinus canicula. Brain Res. Bull. 66, 541-545.

Castro, A., Becerra, M., Manso, M. J., and Anadón, R. (2006). Calretinin immunoreactivity in the brain of the zebrafish, Danio rerio: distribution and comparison with some neuropeptides and neurotransmittersynthesizing enzymes. II. Midbrain, 
hindbrain, and rostral spinal cord. J. Comp. Neurol. 494, 792-814.

Chandrasekhar, A., Moens, C. B., Warren, J.T. Jr., Kimmel, C. B., and Kuwada, J.Y. (1997). Development of branchiomotor neurons in zebrafish. Development 124, 2633-2644.

Coolen, M., Menuet, A., Chassoux, D., Compagnucci, C., Henry, S., Lévèque, L., Da Silva, C., Gavory, F., Samain, S., Wincker, P., Thermes, C., D'AubentonCarafa, Y., Rodríguez-Moldes, I., Naylor, G., Depew, M., Sourdaine, P., and Mazan, S. (2009). "The dogfish Scyliorhinus canicula, a reference in jawed vertebrates," in Emerging Model Organisms. A Laboratory Manual, Vol. 1, eds R. R. Behringer, A. D. Johnson, and R. E Krumlauf (New York: Cold Spring Harbor Laboratory Press), 431-446.

Coolen, M., Sauka-Spengler, T., Nicolle, D., Le-Mentec, C., Lallemand, Y., Da Silva, C., Plouhinec J.-L., Robert, B., Wincker, P., Shi, D.-L., and Mazan, S. (2007). Evolution of axis specification mechanisms in jawed vertebrates: insights from a chondrichthyan. PLoS ONE 2, e374. doi: 10.1371/journal. pone. 0000374

Derobert, Y., Baratte, B., Lepage, M., and Mazan, S. (2002). Pax6 expression patterns in Lampetra fluviatilis and Scyliorhinus canicula embryos suggest highly conserved roles in the early regionalization of the vertebrate brain. Brain Res. Bull. 57, 277-280.

Díaz-Regueira, S., and Anadón, R. (2000). Calretinin expression in specific neuronal systems in the brain of an advanced teleost, the grey mullet (Chelon labrosus). J. Comp. Neurol. 426, 81-105.

Ferreiro-Galve, S., Rodríguez-Moldes, I., and Candal, E. (2010). Calretinin immunoreactivity in the developing retina of sharks: comparison with cell proliferation and GABAergic system markers. Exp. Eye Res. 91, 378-386.

Freitas, R., and Cohn, M. J. (2004). Analysis of EphA4 in the lesser spotted catshark identifies a primitive gnathostome expression pattern and reveals co-option during evolution of shark-specific morphology. Dev. Genes Evol. 214, 466-472.

Gaskell, W. (1886). On the structure, distribution and function of the nerves which innervate the visceral and vascular systems. J. Physiol. 7, 1-81.

Gaskell, W. (1889). On the relation between the structure, function, distribution and origin of the cranial nerves; together with an theory of the origin of the nervous system of vertebrata. J. Physiol. 10, 153-211.

Gilland, E., and Baker, R. (1992). Longitudinal and tangential migration of cranial nerve efferent neurons in the developing hindbrain of Squalus acanthias. Biol. Bull. 183, 356-358.

Gilland, E., and Baker, R. (1993). Conservation of neuroepithelial and mesodermal segments in the embryonic vertebrate head. Acta Anat. (Basel) 148, 110-123.

Gilland, E., and Baker, R. (2005). Evolutionary patterns of cranial nerve efferent nuclei in vertebrates. Brain Behav. Evol. 66, 234-254.

Glover, J. C. (2001). Correlated patterns of neuron differentiation and Hox gene expression in the hindbrain: a comparative analysis. Brain Res. Bull. $55,683-693$.

Hamburger, V., and Hamilton, H. L. (1951). A series of normal stages in the development of the chick embryo. J. Morphol. 88, 49-92.

Herrick, C. J. (1918). An Introduction to Neurology, 2nd Edn. Philadelphia: W.B. Saunders Company.

Heyman, I., Kent, A., and Lumsden, A. (1993). Cellular morphology and extracellular space at rhombomere boundaries in the chick embryo hindbrain. Dev. Dyn. 198, 241-253.

Ju, M. J., Aroca, P., Luo, J., Puelles, L., and Redies, C. (2004). Molecular profiling indicates avian branchiomotor nuclei invade the hindbrain alar plate. Neuroscience 128, 785-796.

Kuratani, S., and Horigome, N. (2000). Developmental morphology of branchiomeric nerves in a cat shark, Scyliorhinus torazame, with special reference to rhombomeres, cephalic mesoderm, and distribution patterns of cephalic crest cells. Zool. Sci. 17, 893-909.

Marín, F., Aroca, P., and Puelles, L. (2008). Hox gene colinear expression in the avian medulla oblongata is correlated with pseudorhombomeric domains. Dev. Biol. 323, 230-247.

Marín, F., and Puelles, L. (1995). Morphological fate of rhombomeres in quail/chick chimeras: a segmental analysis of hindbrain nuclei. Eur. J. Neurosci. 7, 1714-1738.

Morona, R., and González, A. (2009). Immunohistochemical localization of calbindin-D28k and calretinin in the brainstem of anuran and urodele amphibians. J. Comp. Neurol. 515, 503-537.
Murakami, Y., Ogasawara, M., Sugahara, F., Hirano, S., Satoh, N., and Kuratani, S. (2001). Identification and expression of the lamprey Pax6 gene: evolutionary origin of the segmented brain of vertebrates. Development 128, 3521-3531.

Neal, H. V. (1898). The segmentation of the nervous system in Squalus acanthias. Bull. Mus. Comp. Zool. Harvard 31, 147-294.

O'Neill, P., McCole, R. B., and Baker, C.V. (2007). A molecular analysis of neurogenic placode and cranial sensory ganglion development in the shark, Scyliorhinus canicula. Dev. Biol. 304 156-181.

Oulion, S., Debiais-Thibaud, M., d'Aubenton-Carafa, Y., Thermes, C., Da Silva, C., Bernard-Samain, S. Gavory, F., Wincker, P., Mazan, S., and Casane, D. (2010). Evolution of Hox gene clusters in gnathostomes: insights from a survey of a shark (Scyliorhinus canicula) transcriptome. Mol. Biol. Evol. 27, 2829-2838

Prince, V. E., Moens, C. B., Kimmel, C. B., and Ho, R. K. (1998). Zebrafish hox genes: expression in the hindbrain region of wild-type and mutants of the segmentation gene, valentino. Development 125, 393-406.

Pritz, M. B. (1999). Rhombomere development in a reptilian embryo. J. Comp. Neurol. 411, 317-326.

Puelles, L. (2001). Brain segmentation and forebrain development in amniotes. Brain Res. Bull. 55, 695-710.

Rodríguez-Moldes, I., Ferreiro-Galve, S., Carrera, I., Sueiro, C., Candal, E. Mazan, S., and Anadón, R. (2008). Development of the cerebellar body in sharks: spatiotemporal relations of Pax6 expression, cell proliferation and differentiation. Neurosci. Lett.432, 105-110.

Sieber, M. A., Storm, R., Martinez-dela-Torre, M., Müller, T., Wende, H., Reuter, K., Vasyutina, E., and Birchmeier, C. (2007). Lbx1 acts as a selector gene in the fate determination of somatosensory and viscerosensory relay neurons in the hindbrain. $J$. Neurosci. 27, 4902-4909.

Straka, H., Baker, R., and Gilland, E. (2002). The frog as a unique vertebrate model for studying the rhombomeric organization of functionally identified hindbrain neurons. Brain Res. Bull. 57 , 301-305.

Sueiro, C., Carrera, I., Molist, P., Rodríguez-Moldes, I., and Anadón, R. (2004). Development and distribution of glutamic acid decarboxylase (GAD)-immunoreactive systems in the spinal cord of the dogfish Scyliorhinus canicula (elasmobranchs). J. Comp. Neurol. 478, 189-206.

Sueiro, C., Carrera, I., Rodríguez-Moldes, I., Molist, P., and Anadón, R. (2003). Development of catecholaminergic systems in the spinal cord of the dogfish Scyliorhinus canicula (elasmobranchs). Dev. Brain Res. 142, 141-150.

Tümpel, S., Cambronero, F., Sims, C., Krumlauf, R., and Wiedemann, L. M. (2008). A regulatory module embedded in the coding region of HoxA2 controls expression in rhombomere 2. Proc. Natl. Acad. Sci. U.S.A. 105, 20077-20082.

Vaage, S. (1969). The segmentation of the primitive neural tube in chick embryos (Gallus domesticus). A morphological, histochemical and autoradiographical investigation. Ergeb. Anat. Entwicklungsgesch. 41, 3-87.

Vaage, S. (1973). The histogenesis of the isthmic nuclei in chick embryos (Gallus domesticus): I. A morphological study. Z. Anat. Entwicklungsgesch. $142,283-314$.

von Kupffer, C. (1906)."Die Morphogenie des Zentralnervensystems," in Handbuch der vergleichenden und experimentellen Entwicklungslehre der Wirbeltiere, Vol. 2, Part 3, ed. O. Hertwig (Jena: Fischer), 1-272.

Conflict of Interest Statement: The authors declare that the research was conducted in the absence of any commercial or financial relationships that could be construed as a potential conflict of interest.

Received: 01 November 2010; accepted: 18 February 2011; published online: 07 March 2011.

Citation: Rodríguez-Moldes I, Carrera I, Pose-Méndez S, Quintana-Urzainqui I, Candal E, Anadón R, Mazan S and Ferreiro-Galve S (2011) Regionalization of the shark hindbrain: a survey of an ancestral organization. Front. Neuroanat. 5:16. doi: 10.3389/fnana.2011.00016

Copyright (c) 2011 Rodríguez-Moldes, Carrera, Pose-Méndez, QuintanaUrzainqui, Candal, Anadón, Mazan and Ferreiro-Galve. This is an open-access article subject to an exclusive license agreement between the authors and Frontiers Media $S A$, which permits unrestricted use, distribution, and reproduction in any medium, provided the original authors and source are credited. 